\title{
Adaptive selection of founder segments and epistatic control of plant height in the MAGIC winter wheat population WM-800
}

\author{
Wiebke Sannemann ${ }^{1 *}$ (D), Antonia Lisker ${ }^{1}$, Andreas Maurer ${ }^{1}$, Jens Léon², Ebrahim Kazman ${ }^{3}$, Hilmar Cöster $^{4}$, \\ Josef Holzapfel ${ }^{5}$, Hubert Kempf ${ }^{5}$, Viktor Korzun ${ }^{6}$, Erhard Ebmeyer ${ }^{7}$ and Klaus Pillen ${ }^{1}$
}

\begin{abstract}
Background: Multi-parent advanced generation intercross (MAGIC) populations are a newly established tool to dissect quantitative traits. We developed the high resolution MAGIC wheat population WM-800, consisting of $910 \mathrm{~F}_{4: 6}$ lines derived from intercrossing eight recently released European winter wheat cultivars.

Results: Genotyping WM-800 with 7849 SNPs revealed a low mean genetic similarity of 59.7\% between MAGIC lines. WM-800 harbours distinct genomic regions exposed to segregation distortion. These are mainly located on chromosomes 2 to 6 of the wheat B genome where founder specific DNA segments were positively or negatively selected. This suggests adaptive selection of individual founder alleles during population development. The application of a genome-wide association study identified 14 quantitative trait loci (QTL) controlling plant height in WM-800, including the known semi-dwarf genes Rht-B1 and Rht-D1 and a potentially novel QTL on chromosome 5A. Additionally, epistatic effects controlled plant height. For example, two loci on chromosomes 2B and 7B gave rise to an additive epistatic effect of $13.7 \mathrm{~cm}$.
\end{abstract}

Conclusion: The present study demonstrates that plant height in the MAGIC-WHEAT population WM-800 is mainly determined by large-effect QTL and di-genic epistatic interactions. As a proof of concept, our study confirms that WM-800 is a valuable tool to dissect the genetic architecture of important agronomic traits.

Keywords: Winter wheat, Multi-parent advanced generation intercross (MAGIC), Plant height, Genome-wide association study (GWAS), Quantitative trait loci (QTL), Segregation distortion, Epistatic effects, Single nucleotide polymorphism (SNP)

\section{Background}

Bread wheat (Triticum aestivum L., $2 \mathrm{n}=6 \mathrm{x}=42$, AABBDD) is one of the three most important crop species globally, with a world production of more than 710 million metric tons [1]. High-resolution QTL studies are still challenging in wheat due to the large genome size (17 GB), polyploid nature and huge amount of repetitive DNA present in wheat. Today, a high genetic marker density is no longer a limiting factor for QTL studies in wheat through the recent advances in genotyping techniques [2]. Therefore, there is an increasing demand for large and

\footnotetext{
* Correspondence: Wiebke.Sannemann@landw.uni-halle.de

${ }^{1}$ Chair of Plant Breeding, Martin Luther University Halle-Wittenberg,

Betty-Heimann Straße 3, 06120 Halle, Germany

Full list of author information is available at the end of the article
}

complex mapping populations. This enables to study the effects of allelic diversity at a higher genetic resolution and statistical power. Bi-parental populations, used for decades in QTL mapping, estimate allelic effects with high statistical power but suffer from a low genetic diversity regarding the worldwide allelic diversity present in wheat [1]. In contrast, association panels try to capture a high amount of genetic diversity by selecting defined samples from the whole population. This leads to high genetic diversity within the panel but reduced statistical power to detect rare allele effects [1]. Therefore, multi-parent populations are proposed to build a bridge between the two classical QTL mapping populations. They combine higher genetic diversity among the offspring based on an increased number of founders with higher statistical power [1]. The most

(c) The Author(s). 2018 Open Access This article is distributed under the terms of the Creative Commons Attribution 4.0 International License (http://creativecommons.org/licenses/by/4.0/), which permits unrestricted use, distribution, and reproduction in any medium, provided you give appropriate credit to the original author(s) and the source, provide a link to the Creative Commons license, and indicate if changes were made. The Creative Commons Public Domain Dedication waiver (http://creativecommons.org/publicdomain/zero/1.0/) applies to the data made available in this article, unless otherwise stated. 
noteworthy designs, which were successfully used to study multi-parental populations, are nested association mapping (NAM) [3, 4] and multi-parent advanced generation intercrosses (MAGIC), the latter following a mating design according to Cavanagh et al. [5]. MAGIC populations proved their usefulness in several species like Arabidopsis [6], rice [7], barley [8], maize [9], tomato [10] and wheat $[2,11-13]$. So far, two bread wheat MAGIC populations are established. The first was developed by inter-mating four Australian spring wheat cultivars pioneering the setup and statistical analysis of MAGIC populations in crops [11]. The NIAB MAGIC population was second, developed by intercrossing eight winter wheat founders selected to represent the diversity of the UK wheat germplasm [2]. Its usefulness was proved by locating genes controlling the presence of awns [2]. Subsequently, Gardner et al. [13] constructed a population specific genetic map for the MAGIC NIAB population using $\mathrm{R}$ package mpMap [14]. The same statistical methods were applied in a four-way durum wheat MAGIC population as a proof of concept [12]. The NIAB-MAGIC population was used to map genes regulating plant senescence in wheat [15].

Plant height is a key trait in wheat as it affects grain yield, grain quality [16] and pathogen resistance, for instance against Fusarium [17]. The introduction of several reduced height (Rht) genes controlling the gibberellic acid (GA) pathway in wheat, served as a catalyst for the green revolution [18]. The semi-dwarf alleles of Rht-B1 on $4 \mathrm{~B}$ and $R h t-D 1$ on $4 \mathrm{D}$ represented major sources to achieve reduced plant height in European wheat breeding programs since the 1960s. This resulted in markedly increased grain yields in most environments [19]. The semi-dwarfing gene $R h t 8$ is widely used in dry environments of Southern and Eastern European environments [20]. Further, several other semi-dwarfing genes are known, like Rht4, Rht5, Rht6 [21], Rht7 [22], Rht9 [23], Rht11 [24], Rht12 [25], Rht13 to Rht20 [24], however, they are not yet integrated in European wheat breeding programs.

In addition to the known Rht genes, several genetic regions were identified by QTL analysis investigating plant height in various wheat mapping populations $[11,16,26,27]$. A number of plant height QTL could be mapped in each population. However, all populations shared the semi-dwarf effects of the major plant height genes Rht-B1 and Rht-D1, supporting the idea that these two genes are widely used in modern wheat breeding to control plant height.

Epistasis, the genetic interaction between independent loci, is one additional factor known to play an important role in dissecting quantitative traits [28]. Epistasis has been investigated in crops like maize [29], potato [30], barley $[4,31]$ and wheat $[16,32,33]$. The relevance of epistasis has further been proven through genomic selection studies. An increase in prediction accuracy was reported when modelling main and epistatic effects [34,
35]. The authors stated that a large population size and a high marker density are necessary pre-requisites to apply a full marker by marker model and to successfully estimate the contribution of epistasis to the regulation of quantitative traits.

In this study, we report on the new MAGIC winter wheat population WM-800. WM-800 was characterized based on genotypic data derived from a $15 \mathrm{k}$ Infinium iSelect SNP array. This data was applied to investigate genetic diversity, linkage disequilibrium, allele frequency and segregation distortion. We further proved that WM-800 is a powerful mapping tool by dissecting the genetic architecture of plant height. We also demonstrated that epistatic interactions play a significant role controlling plant height in WM-800.

\section{Methods}

\section{Development of WM-800}

WM-800 was developed following the crossing scheme reported by Cavanagh et al. [5]. The WM-800 founders are eight European winter wheat cultivars (Table 1, Additional file 1: Table S1) released between 2008 and 2017. They were selected based on their market dominance regarding yield, baking quality and pathogen resistance. Together, the founders represented a market share of 14,582 ha (31\%) of the German certified seed production in 2014 (Table 1). They were crossed by RAGT $2 \mathrm{n}$ and Syngenta in four pairs to create the $F_{1}$ seeds: Patras $x$ Meister (AB), Linus x JB Asano (CD), Tobak x Bernstein $(\mathrm{EF})$ and Safari $\mathrm{x}$ Julius $(\mathrm{GH})$. Single $\mathrm{F}_{1}$ plants of each 2-way cross were intercrossed, resulting in two 4-way crosses (ABCD) and (EFGH). Subsequently, 141 seeds of the 8-way cross (ABCDEFGH) were produced by Syngenta, where 56 seeds derived from intercrossing 18 4-way $\mathrm{F}_{1}$ plants $(\mathrm{ABCD} \times \mathrm{EFGH})$ and 85 reciprocal 4-way $\mathrm{F}_{1}$ plants (EFGH x ABCD), respectively, to assure a balanced allele frequency for each of the eight founders. On average 15 selfed $\mathrm{F}_{2}$ seeds per 8-way plant were produced. These seeds were further advanced by single seed descent (SSD) to yield $2125 \mathrm{~F}_{4}$ recombinant inbred lines (RILs). Each WM line is expected to hold $12.5 \%$ of the genome of each of the eight WM founders. Altogether, 1323 WM lines were randomly selected and analysed with KASP marker on the presence of double dwarfism at KWS SAAT SE, Einbeck. Out of these, 935 RILs were not homozygous at both loci for the dwarfing allele Rht-B1 and Rht-D1 according to the KASP marker analysis. These were propagated $\left(\mathrm{F}_{4: 5}\right)$ for one round of bulk propagation to establish the MAGIC wheat population WM-800, which is composed of a final set of 910 RILs in $F_{4: 6}$.

\section{Measuring plant height in WM-800}

Bulk propagation of WM-800 RILs took place at Syngenta's breeding station in Hadmersleben, Germany (51 $98^{\prime} 29.07^{\prime \prime}$ 
Table 1 Founder information and plant height descriptive statistics for WM-800 lines and founders

\begin{tabular}{|c|c|c|c|c|c|c|c|c|c|c|c|c|c|c|}
\hline Genotype $^{a}$ & Breeder & Release & $\begin{array}{l}\text { Multiplication } \\
\text { area } 2014 \text { (ha) }\end{array}$ & Quality group & $\begin{array}{l}\text { Crossing } \\
\text { position }^{b}\end{array}$ & Rht-B1 ${ }^{c}$ & Rht-D1 ${ }^{d}$ & $\mathrm{~N}^{e}$ & $\left.\mathrm{HEI}\right|^{f}$ & $S D^{g}$ & $\operatorname{Min}^{h}$ & Maxi & CV (in \%) & $h^{2 k}$ \\
\hline Patras & DSV & 2012 & 2884 & A & A & Rht-B1a & Rht-D1b & 7 & 82.0 & 4.0 & 77.0 & 87.0 & 4.83 & \\
\hline Meister & RAGT & 2010 & 212 & A & B & Rht-B1a & Rht-D1a & 7 & 81.1 & 7.2 & 75.0 & 95.0 & 8.93 & \\
\hline Linus & RAGT & 2010 & 917 & A & C & Rht-B1a & Rht-D1b & 7 & 78.3 & 4.0 & 74.0 & 84.0 & 5.09 & \\
\hline JB Asano & Breun & 2008 & 4044 & A & D & Rht-B1a & Rht-D1b & 22 & 83.4 & 4.9 & 71.0 & 92.0 & 5.88 & \\
\hline Tobak & W von $B$ & 2011 & 3385 & B & E & Rht-B1b & Rht-D1a & 60 & 83.8 & 4.6 & 69.0 & 93.0 & 5.46 & \\
\hline Bernstein & Syngenta & 2014 & 154 & E & $\mathrm{F}$ & Rht-B1a & Rht-D1a & 10 & 96.0 & 9.2 & 82.0 & 107.0 & 9.58 & \\
\hline Safari & Syngenta & 2017 & & C & G & Rht-B1b & Rht-D1a & 7 & 81.9 & 4.1 & 75.0 & 87.0 & 5.06 & \\
\hline Julius & KWS & 2008 & 2986 & A & $\mathrm{H}$ & Rht-B1a & Rht-D1b & 8 & 86.9 & 5.5 & 76 & 92 & 6.29 & \\
\hline \multicolumn{2}{|c|}{ Founder total or mean } & & 14,582 & & & & & 128 & 84.2 & 6.4 & 69.0 & 107.0 & 7.55 & 0.90 \\
\hline \multicolumn{2}{|c|}{ WM-800 total or mean } & & & & & & & 910 & 80.1 & 11.2 & 45.5 & 112.0 & 14.30 & 0.90 \\
\hline
\end{tabular}

${ }^{a}$ Discrimination Founders and MAGIC-WHEAT WM-800 lines

${ }^{b}$ Position in crossing scheme of the WM-800

${ }^{C} R h t-B 1$ genotype based on SNP TG0010a (bold genotype causes semi-dwarfism)

${ }^{\mathrm{d}}$ Rht-D1 genotype based on SNP TG0011a (bold genotype causes semi-dwarfism)

eNumber of observations

fPlant height Lsmeans (in cm)

${ }^{9}$ Standard deviation

${ }^{\mathrm{h}}$ Minimum

'Maximum

'Coefficient of variation [in \%]

kHeritability

$\mathrm{N} ; 11^{\circ} 29^{\prime} 93.28^{\prime \prime}$ E). Plant height (HEI) was measured in one replication on single plants in 2015 and in one replication in field plots $\left(1.50 \times 2.20 \mathrm{~m}\right.$ with 330 viable seeds $\left./ \mathrm{m}^{2}\right)$ in 2016 . Subsequently, analysis of variance for plant height was carried out with SAS 9.4 (SAS Institute Inc., Cary, NC, USA) using PROC MIXED to test for genotype and year effects. Least squares means (LSmeans) per genotype were calculated using PROC MIXED (SAS 9.4) assuming fixed genotype effects and random year effects. PROC VARCOMP (SAS 9.4) was used to estimate variance components. Broad-sense heritability $\left(\mathrm{h}^{2}\right)$ was calculated applying the formula $h^{2}=V_{G} /\left(V_{G}+V_{G Y} / y+V_{R} /\left(y^{*} r\right)\right)$, where $V_{G}, V_{G Y}$ and $V_{R}$ denote the variance components genotype, genotype by year and residual, respectively. $\mathrm{Y}$ and $\mathrm{r}$ denote the number of years and replicates per genotype, respectively.

\section{Genotyping single nucleotide polymorphism (SNP) markers in WM-800}

Bulked DNA from $12 \mathrm{~F}_{4: 5}$ seedlings was extracted for 935 MAGIC wheat lines at TraitGenetics, Gatersleben, Germany (www.traitgenetics.com). Infinium $15 \mathrm{k}$ iSelect SNP array was used for genotyping. It contains 13,006 SNPs selected from the wheat $90 \mathrm{k}$ SNP array [36], including a small set of known genes like Ppd, Rht, Vrn-1 and Vrn-2.

Polymorphic SNP data was quality checked. SNPs with missing data $>10 \%$, heterozygous genotypes $>10 \%$ and minor allele frequency $<1 \%$ were removed [37]. The genetic positions published in the wheat consensus map [36] were used as a reference to assign SNPs to wheat chromosomes and place them in a linear order. SNPs, which could not be assigned to the wheat consensus map [36] were fitted using chi-square test [4]. Genotype data was transcribed into a binary code based on an identity-by-state (IBS) matrix according to the presence of the Julius founder allele. For this, homozygous genotypes carrying two Julius (J) or Non-Julius alleles (N) were assigned a value of 2 and 0 , respectively. Heterozygous genotypes were assigned a value of 1 . Missing genotypes were predicted applying the mean imputation (MNI) approach [38]. Each missing SNP value was replaced by the mean SNP value calculated across all WM-800 genotypes. We selected Julius as the reference founder since the cultivar was selected for the 10 Wheat Genomes Project (see: www.wheatinitiative.org) and since a BLAST database of wheat genome assemblies, including Julius, is available (see webblast.ipk-gatersleben.de/wheat_ten_genomes/).

\section{Allele frequency and segregation distortion in WM-800}

The IBS-SNP matrix was used to calculate allele frequencies and segregation distortion (SD) for each SNP in WM-800. Bi-allelic SNPs do not follow a Mendelian segregation in an 8-way MAGIC population. The segregation ratio of the two alternative SNP alleles in the population depends on their frequency in the founder set. Thus, the SNPs were classified into seven allele frequency groups (AFG 1 - AFG 7), depending on the presence of the Julius allele among the founders. Segregation distortion within each AFG was estimated by chi-square testing, using PROC FREQ (SAS 9.4). Subsequently, Bonferroni-Holm 
correction of the $p$-values ( $p_{\text {Bon-Holm }}$ ) was used for multiple testing with PROC MULTTEST (SAS 9.4) [39]. A chromosomal segregation distortion region (SDR) was defined if at least three adjacent SNP loci showed a significant segregation distortion with $\mathrm{p}_{\text {Bon-Holm }}<0.01$ [40]. AFG 1 and AFG 7 are of particular interest, because allele effects can be assigned to a single founder within these AFGs. The allele effect can be directly assigned to founder Julius in AFG 1 with a founder allele segregation of 1 (Julius allele) to 7 (Non-Julius allele). In addition, AFG 7 with a founder allele segregation of 7 (Julius allele) to 1 (Non-Julius allele) can be further divided into seven subgroups according to the WM-800 founder carrying the Non-Julius allele.

\section{Genetic similarity and linkage disequilibrium in WM-800} Procedure PROC DISTANCE (SAS 9.4) with method simple matching was used to calculate genetic similarity (GS) between WM-800 lines and their eight founders. Subsequently, population structure within WM-800 and their founders was investigated based on GS values applying a principal component analysis (PCA) with PROC PRINCOMP (SAS 9.4).

Linkage disequilibrium (LD) was calculated as the squared allelic correlation linkage $\left(r^{2}\right)$ [41] using the $R$ packages "genetics" and "LDHeatmap". The estimated $r^{2}$ values were plotted against the genetic distance according to [36]. The second-degree smooth locally weighed polynomial regression (LOESS) curve was estimated with PROC LOESS (SAS 9.4). A population-specific background LD $\left(\mathrm{r}^{2}\right)$ was estimated as the 95th-percentile of $\mathrm{r}^{2}$ values for unlinked markers [42].

\section{Genotypic data and genome-wide association study (GWAS)}

The multiple linear regression model "Model-A" was used to conduct GWAS mapping based on plant height LSmeans for each WM-800 line. The model [43] was successfully adapted to a barley MAGIC population [44]. Analysis was carried out with PROC GLMSELECT (SAS 9.4) including 20 times five-fold cross-validation. Stepwise forward and backward selection of significant SNPs was conducted with model selection criteria of $p \leq 0.001$. SNPs were accepted as significant marker-trait associations (MTA) if they were included in the final model in at least 35 cross-validation runs (detection rate $\geq 35 \%$ ) and if $\mathrm{p}_{\text {Bon-- }}$ Holm $<0.01$ after adjusting $p$-values for multiple testing with the Bonferroni-Holm procedure using PROC MULTTEST (SAS 9.4) [39]. MTAs were grouped to a QTL if significant SNPs were placed in a window of $\leq 5 \mathrm{cM}$ and if they revealed additive effects of the same direction [4].

Epistatic effects between SNPs were estimated with the PROC MIXED (SAS 9.4) procedure including a five-fold cross validation based on LSmeans of WM-800 lines as input and a marker 1 by marker 2 interaction to test for fixed interaction effects including a forward selection procedure. At first, markers with a single marker probability below 0.15 were included in pairwise marker interaction analysis. Second, a forward and backward selection procedure was applied for all significant marker by marker combinations. A FDR corrected p-value of $\leq 0.01$ was chosen as a significance threshold to accept the presence of an epistatic effect. Explained marker by marker variance was calculated by comparing the sum of squares of the respective $M$ by $M$ interaction to the sum of squares of the genotypes. Values are given in percent. Marker interactions were grouped to a single interaction if significant SNP interactions were placed in a window $\leq 7 \mathrm{cM}$. Subsequently, the additive by additive epistatic effect (aa) was estimated [45]: aa $=(J J+N N)-(J N+N J)$ where JJ and $\mathrm{NN}$ represent the mean performances of WM-800 lines possessing two Julius, respectively two Non-Julius genotypes, at the two interacting SNPs. JN and NJ represent the mean performances of WM-800 lines possessing a Julius genotype at the first SNP and a Non-Julius genotype at the second SNP and vice versa.

\section{Results and discussion}

\section{Phenotypic characterization of WM-800}

For plant height, a high level of diversity was observed in population WM-800 displaying a range from 45.5 to $112.0 \mathrm{~cm}$ (Fig. 1, Table 1). Detailed information on plant height variation in WM-800 and founder cultivars is given in Table 1 and in Additional file 1: Table S2. On average, WM lines were shorter than the founders with Lsmeans of 80.1 and $84.2 \mathrm{~cm}$, respectively (Table 1 ). In contrast, WM lines displayed a higher coefficient of variation than the founders with 14.25 and $7.55 \%$, respectively. This observation indicates the presence of transgressive segregation in WM-800, where 42 and 79 WM lines are significantly taller and shorter than the tallest (Bernstein) and shortest (Linus) founder cultivar, respectively (Additional file 1: Table S2). In addition, broad sense heritability among WM lines was high with $\mathrm{h}^{2}=0.90$ (Table 1 ). Both findings, transgressive segregation and a high level of heritability, are supportive to locate loci controlling plant height in WM-800 based on a genome-wide association study.

\section{SNP genotyping in WM-800}

Altogether, 7849 polymorphic SNPs were genotyped in WM-800 (Additional file 1: Table S1 and S3). Out of these, 6721 SNPs were assigned to a genetic position [36]. In addition, 863 SNPs (11\%) were mapped based on chi-square association with mapped SNPs [4]. The residual 265 SNPs remained unassigned. About 41.0, 48.2, and $10.7 \%$ of the SNPs were mapped to the A, B, and D subgenomes, respectively. The map length amounted to $3588 \mathrm{cM}$, with individual chromosome lengths ranging 


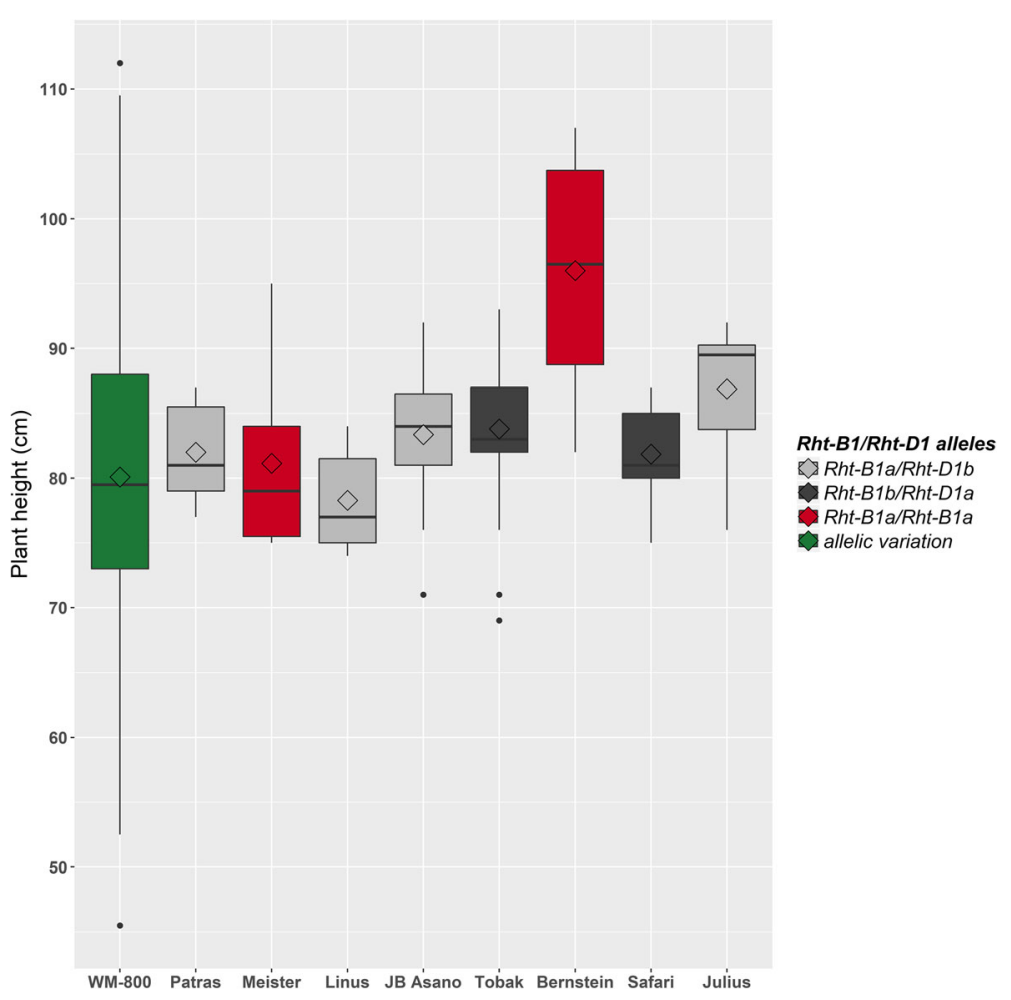

Fig. 1 Plant height variation among WM-800 lines and founders in regard to Rht-B1 and Rht-D1 alleles

from $114.9 \mathrm{cM}(4 \mathrm{~B})$ to $214.8 \mathrm{cM}(7 \mathrm{D})$ and a mean chromosome length of $170.9 \mathrm{cM}$ (Additional file 1: Table S3). SNP density across the three genomes reached $2.2 \mathrm{SNPs} / \mathrm{cM}$. However, this value differed between the subgenomes with 2.5, 3.2 and 0.7 SNPs/cM for the A, B, and D subgenomes, respectively. Also, SNPs were unequally distributed across homeologous chromosomes with the lowest coverage of 613 SNPs (8.1\%) on homeologous group 4 and the highest coverage of 1270 SNPs $(16.8 \%)$ on homeologous group 5 (Additional file 1: Table S3). The highest number of SNPs was mapped to chromosome 5B with 646 SNPs and the lowest number of SNPs to chromosome 4D with 47 SNPs. Over all, the marker distribution showed a high degree of SNP clustering surrounding the centromeres, several major gaps between adjacent SNPs and a low marker density on the D genome. The biggest gap between flanking SNPs was observed on chromosome 7D with $61.5 \mathrm{cM}$. The same observation was previously reported [2], indicating the low amount of diversity present in the $\mathrm{D}$ genome of hexaploid wheat. This finding once again emphasizes the need to selectively increase the number of potentially informative SNPs on arrays originating from the D genome [46].

\section{LD in WM-800}

The analysis of linkage disequilibrium revealed a strong decay of LD with $\mathrm{r}^{2}=0.2$ at $6.8 \mathrm{cM}$. The critical value of the 95th percentile of unlinked SNPs was estimated with $r^{2}=$
0.02 (13.8 cM) (Additional file 2: Fig. S1). The investigation of LD decay per subgenome and per chromosome confirmed the detected pattern, although $\mathrm{r}^{2}$ values varied between subgenomes and chromosomes, conforming the results of Neumann et al. [47] and Würschum et al. [48] (Additional file 1: Table S4). The vertical bands of high $r^{2}$ probably arise from incorrect mapping of SNPs to the consensus map (Additional file 2: Figure S1). Similar results were detected for $\mathrm{LD}$ on chromosome $5 \mathrm{~A}$ and $7 \mathrm{~A}$ [2]. In future, we expect that these questionable mappings may be resolved based on the anticipated completion of the wheat genome sequence. The rapid LD decay within WM-800 corresponded to results from wheat association panels with a mean LD of $3 \mathrm{cM}$ [49]. Compared to already existing MAGIC wheat populations showing a $\mathrm{r}^{2}=0.2$ within $40 \mathrm{cM}$ in the Australian four-way-MAGIC Wheat population [11], the LD decay of $6.8 \mathrm{cM}$ in WM-800 is quite rapid. We assume that this finding may be attributed to the broader genetic variation, which is present between the founders of WM-800, and to the extra round of intercrossing to combine eight founders rather than four. Both aspects may have resulted in a faster LD decay, which in turn builds an optimal foundation for high-resolution mapping and genome wide association studies. In general, independent from different mapping populations, $\mathrm{LD}$ has a slower decay within the $\mathrm{D}$ genome compared to the $\mathrm{A}$ and $\mathrm{B}$ genomes [2, 50], a finding we could confirm in WM-800 (Additional file 1: Table S4). 


\section{Genetic similarity in WM-800}

The analysis of genetic similarity (GS) in WM-800 was based on 7849 SNPs and revealed a low degree of genetic similarity among the eight founders, ranging from $51.6 \%$ (between Patras and Safari) to 65.5\% (between Meister and Bernstein) with a mean GS of $58.1 \%$. These results indicate the high level of diversity between the selected elite soft winter wheat cultivars originating from diverse European breeding programs. Genetic similarity between WM lines ranged from 44.7 to $97.2 \%$ with a mean of $59.7 \%$ (Additional file 1: Table S5). The analysis of principal components (PCA) was used to investigate structure within the population. The first and the second principle components explained 19.2 and 7.5\%, respectively (Fig. 2., Additional file 1: Table S6). Based on the PCA, the WM lines are evenly distributed including the eight founders. We presume that no robust genetic structure is present in WM-800.

\section{SNP allele frequencies in WM-800}

The calculation of the expected SNP allele frequencies in population WM-800 is more complex compared to a bi-parental population. The expected allele frequency in WM-800 depends on the number of founders sharing the same allele. We defined seven allele frequency groups (AFG) depending on the expected allele frequency of the Julius allele (Table 2). Julius is currently used as one cultivar for re-sequencing the hexaploid wheat genome. Therefore, the Julius alleles may be known ahead of other WM founder alleles, being useful for functional annotation of
QTL candidate genes in WM-800. In WM-800 the number of SNPs per AFG followed the number of founders sharing the Julius allele, starting with 260 mapped SNPs in AFG 1 and finishing with 2177 mapped SNPs in AFG 7 (Table 2). The mean allele frequency of the Julius allele increased from 13.5 to $87.1 \%$ and generally corresponded very well to the expected allele frequency in each AFG. The SNP distribution of the Julius allele frequency shifted towards the right due to the increasing number of SNPs from AFG 1 to AFG 7 (Fig. 3). In total, 2437 mapped SNPs (32.1\%) clustered into AFG 1 and AFG 7, indicating the presence of unique SNP alleles in WM-800, which can be traced back to a single WM-800 founder, either Julius (in AFG 1) or one of seven Non-Julius founders (in AFG 7) (Table 2). We consider the frequency of $32.1 \%$ unique SNPs in WM-800 as very high. This observation may support the power of a subsequent QTL detection since no additional founders will dilute the true effect of a founder QTL allele. Among the mapped SNPs, the maximum and minimum number of unique SNPs originated from Safari (5.3\%) and Meister (2.6\%) (Table 2). This finding indicates a relatively even distribution of unique SNPs among the eight WM founders and supports the results of the genetic diversity study.

\section{Segregation distortion in WM-800}

Segregation distortion (SD) is a common phenomenon in plant genome analysis and has been described in many species, like barley [51, 52], triticale [53] and wheat [13, 40, 54].

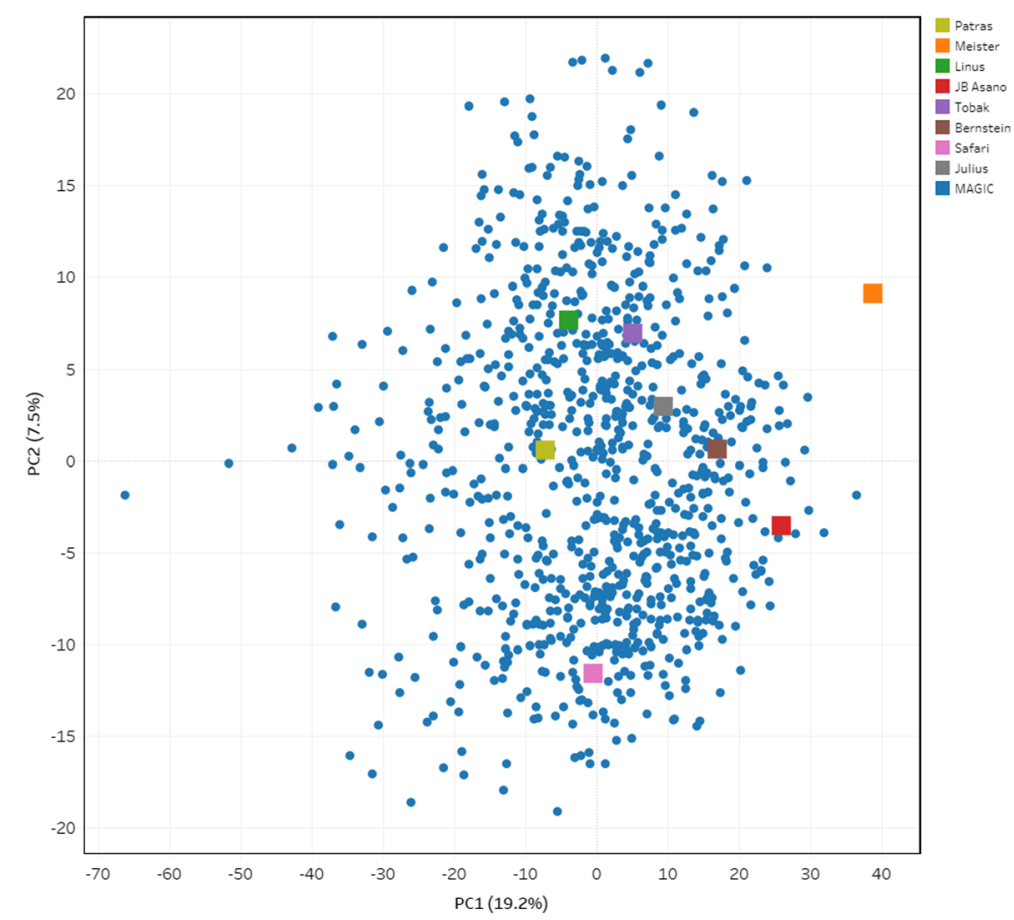

Fig. 2 PCA with 910 MAGIC lines and eight founders based on GS estimated from 7849 SNPS 
Table 2 SNP segregation in seven allele frequency groups (AFG) and expected, observed frequency of Julius alleles

\begin{tabular}{|c|c|c|c|c|c|}
\hline Allele frequency group & $\begin{array}{l}\text { No of founders carrying } \\
\text { the Julius allele }\end{array}$ & Unique SNPs (\%) & $\begin{array}{l}\text { Observed Julius } \\
\text { allele frequency (\%) }\end{array}$ & $\begin{array}{l}\text { Expected Julius } \\
\text { allele frequency (\%) }\end{array}$ & Unique SNPs (\%) \\
\hline AFG 1 - Unique Julius & 1 & 260 & 3.4 & 13.5 & 12.5 \\
\hline AFG 2 & 2 & 531 & & 25.9 & 25.0 \\
\hline AFG 3 & 3 & 877 & & 37.2 & 37.5 \\
\hline AFG 4 & 4 & 842 & & 48.5 & 50.0 \\
\hline AFG 5 & 5 & 1315 & & 62.2 & 62.5 \\
\hline AFG 6 & 6 & 1582 & & 75.7 & 75.0 \\
\hline AFG 7 & 7 & 2177 & & 87.1 & 87.5 \\
\hline \multicolumn{6}{|l|}{ AFG 7 subgroups } \\
\hline AFG 7 - Unique Patras & & 368 & 4.9 & & \\
\hline AFG 7 - Unique Meister & & 200 & 2.6 & & \\
\hline AFG 7 - Unique Linus & & 382 & 5.0 & & \\
\hline AFG 7 - Unique JB Asano & & 233 & 3.1 & & \\
\hline AFG 7 - Unique Tobak & & 265 & 3.5 & & \\
\hline AFG 7 - Unique Bernstein & & 329 & 4.3 & & \\
\hline AFG 7 - Unique Safari & & 400 & 5.3 & & \\
\hline Sum of unique SNPs $=$ AFG $1+$ AFG7 & & 2437 & 32.1 & & \\
\hline Total number of SNPS & & 7584 & & & \\
\hline
\end{tabular}

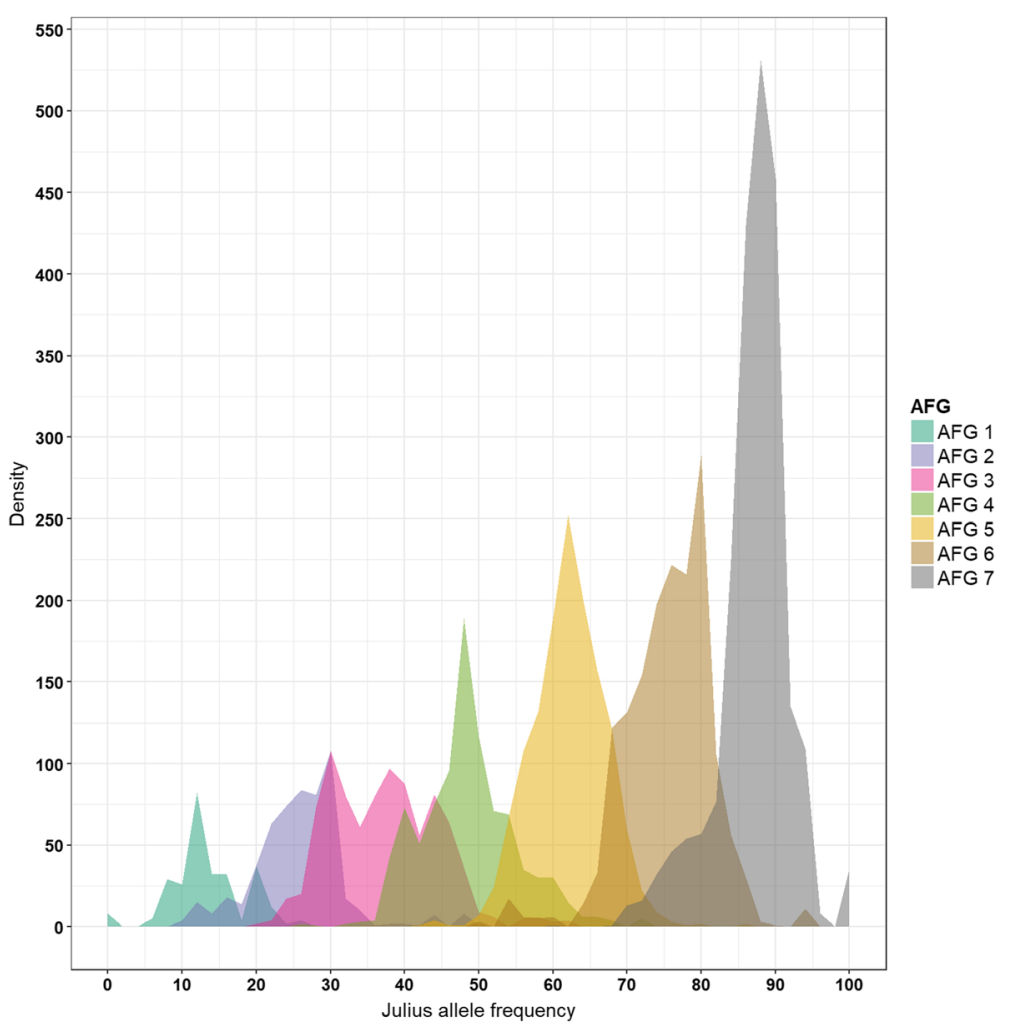

Fig. 3 Frequency distribution of Julius alleles per allele frequency group (AFG) 1 to 7 
It is the deviation of the segregation ratio of a locus from the expected Mendelian ratio [55]. The allele frequency depends on the crossing scheme. In an eight-way MAGIC population it follows a 1:1:1:1:1:1:1:1 segregation, provided that all eight founder alleles can be differentiated. In case of genotyping bi-allelic SNP markers in WM-800, the segregation is reduced to two classes, in our case: Julius allele and Non-Julius allele. Here, the expected allele frequencies depend on the number of founders sharing the Julius allele as indicated in Table 2. Genetic causes for deviation from the expected segregation are selection, either natural or artificial. Allelic selection may take place during gametogenesis or during embryogenesis. However Dreissig et al. [52] and Belanger et al. [56] reported that gametic selection was almost absent in contrast to zygotic selection, when they compared SNP genotyping in pollen and doubled haploids of barley. Zygotic selection may occur during population development and propagation where fitness disparities between alleles or genotypes may result in reduced reproduction rates or even lethality. The latter case is also termed hybrid necrosis caused by genes involved in immunity reactions [57-59]. In all cases, the frequency of the allele or genotype under negative selection is reduced in the final population. In addition, also those alleles, which are genetically linked and, in most cases, jointly inherited to the next generation, will be reduced in the final population depending on the genetic distance between the linked allele and the causative gene under selection.

Segregation distortion in WM-800 was investigated by chi square testing of each SNP according to the expected allele frequency in each AFG (Table 2). To our knowledge, this AFG-specific approach of the investigation of segregation distortion is applied for the first time to a plant MAGIC population. In WM-800, 1417 mapped out of 7584 (18.7\%) SNPs revealed significant SD with $\mathrm{p}_{\text {Bon-Holm }} \leq$ 0.01 (Additional file 1: Table S7). Out of these, 877 SNPs were placed in SDR. SDRs were not evenly distributed across the wheat subgenomes: 210, 612 and 55 distorted SNPs were mapped to the A, B and D subgenomes, respectively. These numbers translate into 6.7, 16.7 and $6.8 \%$ of the SNPs of subgenomes A, B and D, respectively, which were located in distorted segregation regions. SNPs located on subgenome B, thus, were much more frequently exposed to selection, either natural or artificial, during the development of WM-800, than SNPs on subgenomes A and D. Distorted SNPs were predominantly found on chromosomes $2 \mathrm{~B}, 3 \mathrm{~B}, 4 \mathrm{~B}, 5 \mathrm{~A}, 5 \mathrm{~B}, 5 \mathrm{D}$ and $6 \mathrm{~B}$, where between 14.1 and $32.1 \%$ of all chromosomal SNPs showed distorted segregation (Fig. 4, Additional file 1: Table S7).

The proximal segregation distortion region in wheat on chromosome 2B was already reported [40, 54, 60-63]. Since the onset of modern wheat breeding, alien chromosome fragments have been incorporated into bread wheat germplasm to broaden the genetic base, for instance, to improve pathogen resistance. For example, the stem rust and powdery mildew resistance genes $\mathrm{Sr} 36$ and $\mathrm{Pm} 6$ were introgressed from the short arm of chromosome $2 \mathrm{G}$ of $T$. timopheevii [13], which, presumably, resulted in segregation distortion [54, 64]. In WM-800, the founders Meister and JB Asano also contributed the alien Pm6 gene. However, the majority of distorted SNPs were in favour of the Tobak allele suggesting that not the alien fragment carrying founders Meister and JB Asano alone are responsible for SDR on chromosome $2 \mathrm{~B}$ in WM-800. In future, we propose to build haplotype genotypes based on selective exome capture sequencing of the wheat gene space, in order to potentially differentiate all eight founder alleles $[65,66]$. This way, the identification of individual alleles, positively or negatively selected in WM-800, may be enhanced. Furthermore, chromosome $2 \mathrm{~B}$ was reported to host genetic regions responsible for plant regeneration [53]. Potentially genes linked to Ppd might be involved within the process [67]. Also, studies in rice and maize reported SDRs located close to genetic regions harbouring gametophytic factors $[68,69]$.

In contrast to Gardner et al. [13], segregation distortion on chromosome $1 \mathrm{~B}$ was relatively moderate in WM-800. Chromosome 1B harbours the rye translocation 1RS:1BL, which is known to induce SD [70, 71]. However, the diagnostic SNP TG0025 for 1RS:1BL was monomorphic between all founders of WM-800. Therefore, we assume that segregation distortion for chromosome $1 \mathrm{~B}$ did not arise through the translocation $1 \mathrm{RS}: 1 \mathrm{BL}$ as discovered in several publications [13, 72, 73]. Chromosome 3B harboured the highest percentage (32.1\%) of SNPs in SDR in WM-800. Population specific segregation distortion on chromosome $3 \mathrm{~B}$ was also observed in the MAGIC NIAB2015 population [13] and to a lower degree in two wheat RIL populations [73].

The only evidence for artificial selection in WM-800 was found on chromosome 4D. Four SNPs, clustering into one SDR, showed a significant deviation from the expected Mendelian segregation (Additional file 1: Table S7 and S1). This SDR included the SNPs TG0011a and TG0011b, which are diagnostic for the plant height reducing gene $R h t-D 1$. The distorted SNPs were skewed against the semi-dwarf allele $R h t-D 1 b$ with a $13.79 \%$ lower allele frequency than expected. In WM-800, Rht-D1b was simultaneously inherited by four founders, Julius, Patras, Linus and JB Asano. During development of WM-800, 170 double dwarfs, simultaneously containing semi-dwarf alleles at Rht-D1b and Rht-D1b, were removed in generation $\mathrm{F}_{4}$ from 1323 WM-lines based on two diagnostic KASP markers in order to avoid the presence of low-yielding WM lines in the following field studies. Thus, the artificial selection against double dwarfs resulted in a significantly reduced presence of semi-dwarf alleles at the Rht-D1 locus. However, the frequency of the second 


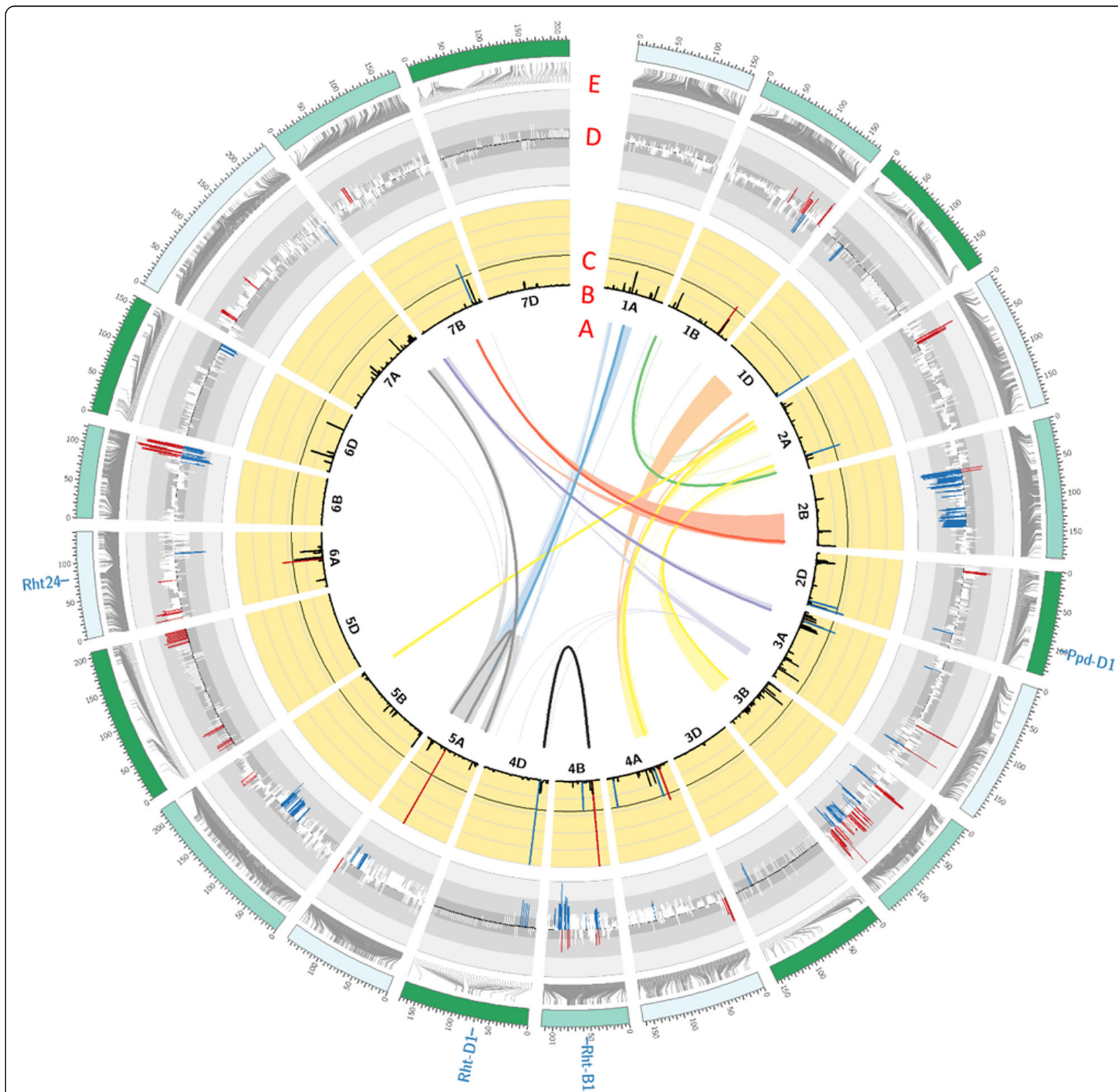

Fig. 4 Circos plot illustrating QTL controlling plant height and SNPs exposed to segregation distortion in WM-800. a) Links in the circle represent significant $\left(P_{F D R} \leq 0.01\right)$ di-genic epistatic interactions between independent SNPs. The firm lines connect the epistatically interacting SNPS remaining after forward and backward selection. b) Chromosome 1A to 7D. c) Bars represent the detection rate of SNPs in 100 cross-validation runs during GWAS. The dark grey line represents the detection rate threshold of $\geq 35 \%$. Coloured bars indicate the 14 significant SNPs identified to control plant height. Red and blue bars symbolize enhancing and reducing effects of the homozygous Julius allele on plant height in WM-800, respectively. d) Segregation distortion regions along the chromosomes. Height of bars symbolized the strength of deviation of the expected Julius allele frequency. Blue and red colours indicate SNPs revealing a decrease and an increase of the Julius allele frequency, respectively. E) Grey connector lines represent the genetic position of the SNP on the wheat chromosome. Position of candidate genes Rht-D1, Rht-B1, Rht24 and Ppd-D1 are indicated outside the Circos plot

semi-dwarf allele, Rht-B1b on chromosome $4 \mathrm{~B}$, was only slightly, but non-significantly, reduced by $3.08 \%$, although this allele was inherited by two WM-800 founders, Tobak and Safari.
In general, a large portion of SNPs in SDRs belong to allele frequency groups AFG 1 and 7, i.e. 49 and 280 SNPs (Additional file 1: Table S7). Investigating SDR in AFG 1 and 7 is helpful to identify chromosomes, which are 
selected in favour or against a particular WM founder. In total, ten major selection events of single founders were identified in WM-800. More than 10 independent SNPs are present, showing an increase of unique alleles from WM founders Tobak (2B), Safari (3B), Linus (4B), Safari (5A), Julius (5B) and Bernstein (6B). Likewise, more than 10 independent SNPs are present, showing a significant decrease of unique alleles from WM founders Patras and Linus (3B), Julius (5B) and Meister (6B) (Additional file 1: Tables S7 and S8). Only WM founder JB Asano was not involved in any major selection event. This finding may indicate the existence of adaptive selection between founder alleles during population development where individual chromosomal segments were positively or negatively selected. It is noticeable that most chromosomes involved in major selection events belong to subgenome B. This finding is in agreement with Gardner et al. [13], who also identified a preponderance of B chromosomes showing SD.

\section{Genome-wide association studies for plant height}

The relatively low average genetic similarity of $59.7 \%$ between WM-800 lines, the strong phenotypic variation of plant height and its high heritability are promising features for a successful GWAS. Consequently, 14 highly significant QTL were estimated regulating plant height in WM-800 with $\mathrm{p}_{\text {Bon-Holm }} \leq 0.001$ (Table 3, Fig. 4). In total, these QTL explained $59.9 \%$ of the cumulated genotypic variance $\left(\mathrm{R}^{2} \mathrm{val}\right)$. Only four QTL explained more than $4 \%$ of the genetic variation. This indicates, that plant height in WM-800 is controlled by a small number of genes revealing strong effects and a larger number of genes exposing small effects. However, approximately $50 \%$ of the genetic variation remains unexplained. This hidden part of genetic control may point to an even larger number of additional genes with small effects. To locate these QTL, an increase of population size, marker density and number of tested environments may be necessary.

The strongest QTL controlling plant height in WM-800 are the semi-dwarf genes $R h t-D 1$ and $R h t-B 1$ on chromosomes 4D and 4B [74]. They explain 21.5\% (Rht-D1) and $6.7 \%$ (Rht-B1) of the genotypic variance (Table 3, Additional file 1: Table S1), This findings are in correspondence with results in association panel [16] and in the Australian four-parent MAGIC Wheat population [11]. The gibberellic acid (GA) insensitive semi-dwarfing alleles $R h t-B 1 b$ and $R h t-D 1 b$ are presumably the most studied plant height reducing genes in wheat. Together, they are present in probably $90 \%$ of the world's semi-dwarf wheat cultivars, strongly reinforcing green revolution in wheat [75]. The homozygous Julius alleles at these two QTL increased plant height relative to the Non-Julius alleles by $12.8 \mathrm{~cm}(R h t-B 1)$ and reduced plant height by $-14.9 \mathrm{~cm}$ $(R h t-D 1)$, respectively. These effects are in accordance with the expected effects inherited by the WM founders (Fig. 1). The Non-Julius founders Tobak and Safari possess the semi-dwarf allele $R h t-B 1 b$ whereas the founders Julius, Patras, Linus and JB Asano possess the semi-dwarf allele Rht-D1b (Table 1). Locating both semi-dwarf genes, $R h t-B 1$ and $R h t-D 1$, with high precision within the MAGIC WM-800 population may serve as a proof of concept. This finding may support the establishment of WM-800 as a precious genetic resource to be used in high resolution mapping and, ultimately, cloning of quantitative genes controlling developmental and agronomic traits in the elite wheat gene pool.

A further strong plant height QTL in WM-800 was located on chromosomes $6 \mathrm{~A}, 79.1 \mathrm{cM}$, explaining $4.8 \%$ of the genotypic variation. At this locus the Julius allele resulted in a $5.1 \mathrm{~cm}$ increase in plant height. The QTL QHEI.WM-800.6A coincided with results from an association panel [76] and from a bi-parental population [77]. The effect can be attributed to the Rht locus $R h t 24$.

In addition to the strong effects mentioned before, a QTL in close proximity to the photoperiod sensitivity gene Ppd-D1 was detected on chromosome 2D. Here, the Julius allele was associated with a plant height reducing effect of $-3.5 \mathrm{~cm}$. The Ppd-D1 effect on plant height was also reported in wheat $[11,16,78]$ and in barley [79], indicating that Ppd-D1 may be involved in controlling a number of developmental traits.

So far, no further candidate genes can be associated to the remaining ten significant QTL regions controlling plant height. Among the numerous small effects, the QTL region on chromosome $5 \mathrm{~A}$ with an effect of $5.3 \mathrm{~cm}$ and $5.5 \%$ of explained genotypic variation harbours great potential for plant height reduction. In future, a follow up study based on exome capture sequencing of informative, recombinant WM offspring lines may be used to fine-map the QTL region and ultimately identify the causative gene. For this, a pair of WM offspring lines need to be selected that segregate for the SNP under investigation and, simultaneously, is fixed for the long straw allele at the remaining 13 plant height QTL regions. This pair can be developed from a WM line heterozygous at the QTL under investigation, following the heterogeneous inbred family (HIF) concept proposed by Tuinstra et al. [80] and successfully applied, for instance, by Liu et al. [81].

\section{Epistatic effects on plant height}

Epistasis refers to a genetic interaction between two or more loci in a genome [82]. Epistasis was used to dissect the genetic architecture of complex traits like flowering time in crops [83]. In WM-800, the analysis of epistatic interactions was based on a di-genic model. In total, eleven epistatic marker*marker interactions controlling plant height were located (Fig. 4). Altogether, these interactions explained $84.1 \%$ of the epistatic variance with 
Table 3 List of 14 QTL controlling plant height in wheat population WM-800 (detection rate $\geq 35$ )

\begin{tabular}{|c|c|c|c|c|c|c|c|c|c|c|}
\hline QTL name ${ }^{a}$ & SNP marker ${ }^{b}$ & $\mathrm{Chr}^{\mathrm{c}}$ & $\operatorname{Pos}^{d}$ & Range $^{e}$ & $D R^{f}$ & $\mathrm{P}_{\text {Bon-Holm }}{ }^{\mathrm{g}}$ & Effect $^{\text {h }}$ & 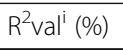 & Candidate gene ${ }^{j}$ & Literature $^{j}$ \\
\hline QHEI.WM-800.1B & CAP8_C5043_190 & 1B & 117.8 & 117.8 & 39 & $6.70 \mathrm{E}-05$ & 3.8 & 0.8 & & \\
\hline QHEI.WM-800.1D & BS00063511_51 & $1 \mathrm{D}$ & 167.1 & 167.1 & 44 & $9.24 \mathrm{E}-05$ & -3.9 & 1.4 & & [16] \\
\hline QHEI.WM-800.2A & Excalibur_c20439_825 & $2 \mathrm{~A}$ & 148.8 & 148.8 & 42 & 6.69E-05 & -2.4 & 1.0 & & \\
\hline QHEI.WM-800.2D & Excalibur_rep_c67599_2154 & $2 \mathrm{D}$ & 97.1 & 97.1 & 35 & 9.37E-06 & -3.5 & 1.3 & Ppd-D1 & [89] \\
\hline QHEI.WM-800.3A & IAAV5729 & $3 \mathrm{~A}$ & 61.1 & 61.1 & 41 & 5.01E-05 & -2.9 & 1.3 & & [26] \\
\hline QHEI.WM-800.4A.a & wsnp_Ex_c5487_9686018 & $4 \mathrm{~A}$ & 43.2 & 43.2 & 42 & $7.25 \mathrm{E}-05$ & 2.8 & 0.8 & & \\
\hline QHEI.WM-800.4A.b & Kukri_c48199_102 & $4 \mathrm{~A}$ & 49.0 & 49.0 & 36 & 4.76E-05 & -2.8 & 1.0 & & \\
\hline QHEI.WM-800.4A.C & wsnp_Ex_c12725_2021270 & $4 \mathrm{~A}$ & 147.2 & 147.2 & 35 & 4.69E-05 & -4.5 & 0.5 & & \\
\hline QHEI.WM-800.4B.a & TG0010a & $4 \mathrm{~B}$ & 56.0 & 56.0 & 100 & $1.25 E-47$ & 12.8 & 6.7 & $R h t-B 1$ & [74] \\
\hline QHEI.WM-800.4B.b & BS00030843_51 & $4 \mathrm{~B}$ & 62.9 & 62.9 & 35 & 3.97E-05 & -2.8 & 0.6 & & \\
\hline QHEI.WM-800.4D & TG0011a & $4 \mathrm{D}$ & 69.2 & 69.2 & 99 & 4.17E-20 & -14.9 & 21.5 & Rht-D1 & [74] \\
\hline QHEI.WM-800.5A & RAC875_C30711_544 & $5 \mathrm{~A}$ & 67.0 & 67.0 & 100 & 1.38E-07 & 5.3 & 5.5 & & \\
\hline QHEI.WM-800.6A & tplb0047k12_1370 & $6 \mathrm{~A}$ & 79.1 & $79.1(2)$ & 47 & $1.44 \mathrm{E}-16$ & 5.1 & 4.8 & Rht24 & [76] \\
\hline \multirow[t]{2}{*}{ QHEI.WM-800.7B } & RAC875_C76528_296 & $7 \mathrm{~B}$ & 155.4 & 155.4-159.7 (2) & 51 & $2.45 \mathrm{E}-05$ & -4.3 & 0.8 & & \\
\hline & & & & & & & & 59.9 & & \\
\hline
\end{tabular}

${ }^{\mathrm{a}} \mathrm{QTL}$ name including trait, population and chromosome information

${ }^{\mathrm{b}} \mathrm{SNP}$ marker name [36]

cChromosome of SNP marker [36]

${ }^{\mathrm{d}}$ Genetic position of SNP marker [36]

${ }^{e}$ Range of QTL in CM including number of significant SNPs (in brackets) within the range

fDetection rate (DR) of SNP by cross validation

${ }^{9}$ Bonferroni corrected $p$-value of SNP marker

hEffect of homozygous Julius allele (in $\mathrm{cm}$ ) compared to non-Julius allele

iCross-validated proportion of explained genetic variance of validation set

${ }^{\mathrm{j} C}$ Candidate genes with references

$\mathrm{R}^{2}$ values ranging from 3.4 to $45.1 \%$ (Table 4 ). In contrast, the estimated epistatic interactions explained only between 0.0 and $3.0 \%$ of the genetic variance for plant height in a set of European winter wheat cultivars [16]. However, a high level of explained genetic variance (77\%) for flowering time was observed in a NAM barley population [4]. The latter authors emphasized (1) the use of multi-parental populations to investigate complex traits, (2) the necessity to investigate epistatic interactions in order to estimate the "missing heritability" and (3) the discovery of, so far, unknown functional gene networks by modelling epistatic effects.

In WM-800, the semi-dwarf genes Rht-B1 and Rht-D1, located on chromosomes $4 \mathrm{~B}$ and $4 \mathrm{D}$, proved to be the major players of di-genic epistatic interactions controlling plant height. This interaction explained a maximum of $45.1 \%$ of the epistatic variance and gave rise to an estimated additive by additive epistatic effect (aa) of $13.2 \mathrm{~cm}$ (Table 4). WM lines possessing two Julius or two Non-Julius alleles at $R h t-B 1$ and $R h t-D 1$ revealed a mean plant height reduction by $-13.2 \mathrm{~cm}$ compared to WM lines possessing a Julius and a Non-Julius allele at both loci. This finding is in agreement with studies of Ellis et al. [74] and Baenziger et al. [84]. More recently, it was reported that wheat genotypes possessing both semi-dwarf alleles simultaneously produced significantly shorter plants [11]. In contrast, several studies on doubled haploid (DH) and recombination inbred line (RIL) populations did not detect the major plant height interaction effect between $R h t-B 1 b$ and Rht-D1b [85-87], possibly due to the presence of low genetic diversity between the parents. The same holds true for Würschum et al. [16] and Zhao et al. [86] who studied epistatic interactions in panels of wheat cultivars and hybrids, respectively. Finding the $R h t-B 1 b$ by $R h t-D 1 b$ epistatic interaction in WM-800 may serve as a proof of concept to include epistatic models in MAGIC populations.

In addition to the Rht-B1 by $R h t-D 1$ interaction ten further epistatic interactions were detected for plant height in WM-800 (Table 4). In most cases (8 out of 11) at least one marker involved in epistasis was associated with a QTL main effect. This finding is in accordance with others who also found markers, which were simultaneously associated with main QTL effects and epistatic effects in wheat [86] and maize [88], respectively. Additional strong epistatic effects were found between markers on different chromosomes, for example between SNPs on chromosomes 3A and 7B with an epistatic effect of $-11.4 \mathrm{~cm}$ (Fig. 5). Epistatic interactions were also found between independent SNPs on the same 
Table 4 Significant epistatic interaction effects for plant height in WM-800

\begin{tabular}{|c|c|c|c|c|c|c|c|c|c|c|c|c|c|}
\hline $\begin{array}{l}\text { Epistatic } \\
\text { Interaction }^{a}\end{array}$ & SNP M1 ${ }^{\mathrm{b}}$ & $\mathrm{Chr}^{\mathrm{c}}$ & $\operatorname{Pos}^{d}$ & SNP M2 ${ }^{b}$ & $\mathrm{Chr}^{\mathrm{c}}$ & $\operatorname{Pos}^{d}$ & $\mathrm{FDR}^{\mathrm{e}}$ & $\mathrm{R}^{2 f}$ & $J / J^{9}$ & $\begin{array}{l}\mathrm{N} / \\
\mathrm{N}^{h}\end{array}$ & $J / N^{i}$ & $N / J^{j}$ & $a a^{k}$ \\
\hline EpiHEI.WM-800.1 & Kukri_c67601_267 & $1 \mathrm{~A}$ & 71.5 & TA001269-1282 & $5 A$ & 62.7 & $\begin{array}{l}3.23 \mathrm{E}- \\
13\end{array}$ & 17.0 & 81.4 & 83.6 & 90.4 & 75.3 & 0.70 \\
\hline EpiHEI.WM-800.2 & BS00050522_51 & 1B & 5.3 & Kukri_c21008_657 & $2 A$ & 151.3 & $\begin{array}{l}2.35 \mathrm{E}- \\
03\end{array}$ & 6.4 & 80.6 & 81.8 & 81.8 & 72.2 & 8.40 \\
\hline EpiHEI.WM-800.3 & Excalibur_c92298_213 & 1D & 171.3 & wsnp_Ex_c539_1072859 & $4 \mathrm{~A}$ & 60.4 & $\begin{array}{l}1.24 \mathrm{E}- \\
02\end{array}$ & 5.4 & 81.3 & 81.1 & 78.1 & 82.3 & 1.80 \\
\hline EpiHEI.WM-800.4 & BobWhite_c11022_78 & $2 \mathrm{~A}$ & 11.5 & TA004056-0809 & $4 \mathrm{~A}$ & 48.5 & $\begin{array}{l}1.38 \mathrm{E}- \\
02\end{array}$ & 3.4 & 80.3 & 80.6 & 87.4 & 79.9 & -6.40 \\
\hline EpiHEI.WM-800.5 & RAC875_c47161_100 & $2 \mathrm{~A}$ & 47.2 & TA004556-0473 & $5 B$ & 176.6 & $\begin{array}{l}3.44 \mathrm{E}- \\
04\end{array}$ & 8.6 & 82.0 & 78.6 & 81.8 & 80.1 & -1.40 \\
\hline EpiHEI.WM-800.6 & RAC875_c9523_328 & $2 A$ & 144.2 & BS00095061_51 & $3 B$ & 67.5 & $\begin{array}{l}1.35 \mathrm{E}- \\
02\end{array}$ & 4.5 & 81.5 & 81.1 & 78.0 & 81.9 & 2.60 \\
\hline EpiHEI.WM-800.7 & TA002989-0535 & $2 B$ & 157.2 & RAC875_rep_c78007_425 & $7 \mathrm{~B}$ & 135.4 & $\begin{array}{l}5.95 E- \\
09\end{array}$ & 9.8 & 78.4 & 96.2 & 81.3 & 79.6 & 13.70 \\
\hline EpiHEI.WM-800.8 & BS00067499_51 & $3 A$ & 68.7 & Tdurum_contig57370_82 & $7 \mathrm{~B}$ & 53.8 & $\begin{array}{l}4.67 \mathrm{E}- \\
04\end{array}$ & 9.7 & 79.8 & 77.4 & 81.9 & 86.7 & -11.40 \\
\hline EpiHEI.WM-800.9 & TG0010a & 4B & 56.0 & TG0011a & 4D & 69.2 & $\begin{array}{l}6.32 \mathrm{E}- \\
44\end{array}$ & 45.1 & 73.9 & 77.7 & 89.0 & NA & -13.20 \\
\hline EpiHEI.WM-800.10 & wsnp_Ra_rep_c69221_665 & $5 \mathrm{~A}$ & 42.0 & Tdurum_contig17062_221 & $7 \mathrm{~A}$ & 202.2 & $\begin{array}{l}3.58 \mathrm{E}- \\
06\end{array}$ & 11.5 & 82.4 & 77.0 & 90.0 & 78.4 & -9.00 \\
\hline \multirow[t]{2}{*}{ EpiHEI.WM-800.11 } & TA001269-1282 & $5 A$ & 62.7 & wsnp_Ex_c1880_3545329 & $5 \mathrm{~A}$ & 104.9 & $\begin{array}{l}3.49 \mathrm{E}- \\
11\end{array}$ & 15.2 & 76.9 & 82.8 & 82.4 & 88.7 & -11.50 \\
\hline & & & & & & & & 84.1 & & & & & \\
\hline
\end{tabular}

${ }^{a}$ Name of epistatic interaction including prefix Epi, trait, population and a consecutive number

${ }^{\mathrm{b}}$ Interacting SNP markers M1 and M2

${ }^{c}$ Chromosomal location of SNP [36]

${ }^{\mathrm{d}}$ Genetic position in CM of SNP [36]

eFDR corrected $p$ value of marker $1 *$ marker 2 interaction

fProportion of explained epistatic variance in \% of marker $1{ }^{*}$ marker 2 interaction (in \%)

${ }^{9}$ Mean plant height (in $\mathrm{cm}$ ) of WM lines carrying homozygous Julius alleles $(\mathrm{J}$ ) at both loci

${ }^{\mathrm{h}}$ Mean plant height (in $\mathrm{cm}$ ) of WM lines carrying homozygous Non-Julius alleles $(\mathrm{N})$ at both loci

iMean plant height (in $\mathrm{cm}$ ) of WM lines carrying a homozygous Julius allele $(\mathrm{J})$ and a Non-Julius allele (N) at loci 1 and 2, respectively

${ }^{\mathrm{j}}$ Mean plant height (in $\mathrm{cm}$ ) of WM lines carrying a homozygous Non-Julius allele $(\mathrm{N})$ and a Julius allele $(\mathrm{J})$ at loci 1 and 2 , respectively

${ }^{k}$ Estimated additive by additive epistatic interaction effect (aa) [45]

Bold letters indicate markers located in regions containing main QTL for plant height (Table 3)

$\mathrm{NA}=$ data not available, in this case, the epistatic interaction effect was estimated by adding twice the mean plant height of the JN group

chromosome, for instance on chromosome 5A producing an estimated additive by additive epistatic effect of - $11.5 \mathrm{~cm}$ (Table 4). So far, no candidate genes are available to explain these epistatic interactions. Our findings support the idea that epistatic interactions need to be taken into account to explain a maximum of the genetic variation present in MAGIC populations. WM-800 serves as an ideal source to apply epistatic models. The population is larger than standard mapping populations. The chance to detect epistatic interactions is increased because eight rather than two alleles segregate at each investigated locus. In future, we propose to increase the number of genotyped markers in WM-800 and to transform bi-allelic SNP marker into multi-allelic haplotype markers in order to increase the odds to detect epistatic interacting loci and to fine-map and, ultimately, clone the causative genes, which epistatically interact in a gene network.

\section{Conclusion}

The genetic structure of the multi-parental population WM-800 enables to conducted detailed studies on the genetic architecture of important agronomic traits in wheat, exemplified by plant height as a proof of concept. In the present study we demonstrated that plant height in WM-800 is mainly determined by large-effect QTL and di-genic epistatic interactions. The semi-dwarf genes $R h t-B 1$ and Rht-D1 turned out to be prominent in both cases. In addition, a number of regions, predominantly on the subgenome $\mathrm{B}$ chromosomes $2 \mathrm{~B}, 3 \mathrm{~B}, 4 \mathrm{~B}, 5 \mathrm{~B}$ and $6 \mathrm{~B}$, could be identified to suffer from segregation distortion. Most SDRs turned out to be WM founder specific, indicating a predominantly subgenome B chromosome-specific selection against or in favour of WM founder alleles during the development of WM-800. Although no artificial selection was applied except for the occurrence of double dwarfs on chromosomes 4B and 4D (Rht-B1 and Rht-D1). 


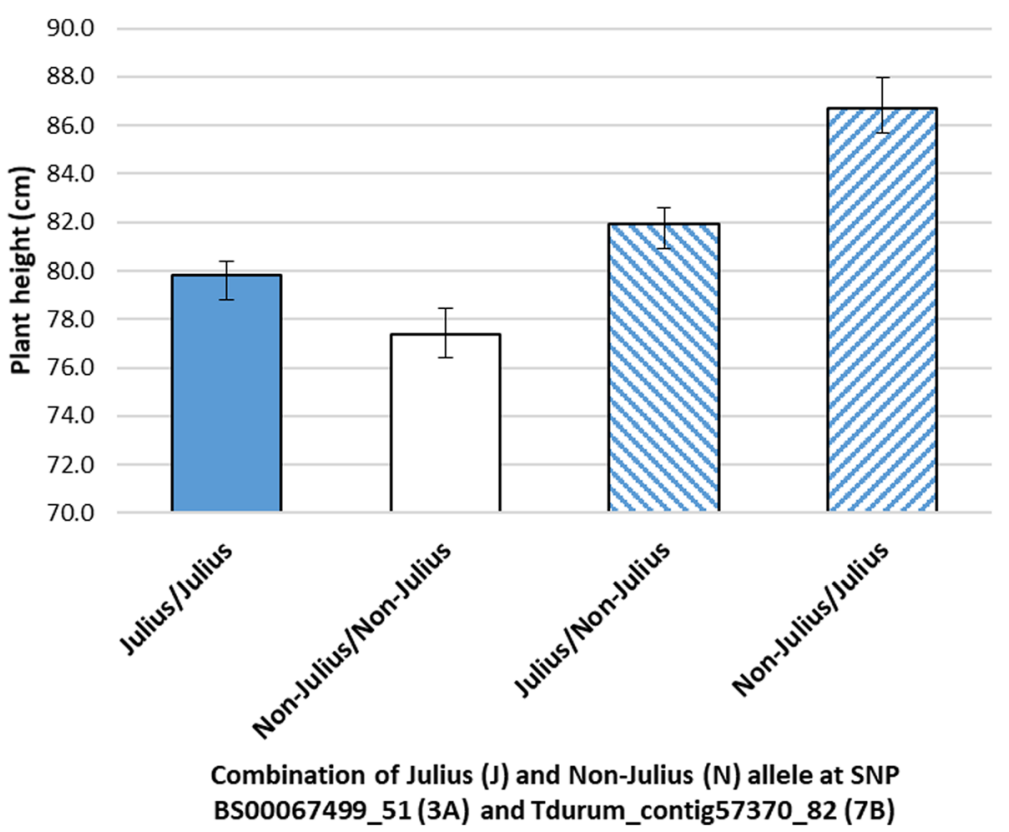

Fig. 5 Epistatic effect of EHEI.WM-800.8. at chromosome 3A, 68.7 cM and 7B, $53.8 \mathrm{cM}$

Our first findings demonstrate the high value of WM-800 to support both - genetic studies to explain genetic networks regulating quantitative traits as well as breeding improved wheat cultivars. Regarding the latter aspect, we propose to evaluate WM-800 for direct selection of improved winter wheat cultivars. Both routes are currently followed up in our MAGIC-WHEAT consortium consisting of wheat geneticists and applied wheat breeders.

\section{Additional files}

Additional file 1 Table S1. SNP genotypes, plant height, QTL detection rate and genotype and allele frequencies for 910 MAGIC WHEAT lines and eight founders. Table S2. Plant height $(\mathrm{cm})$ raw data for MAGIC WM-lines and founders for year 2015 and 2016. Table S3. Distribution of polymorphic SNPs within WM-800 according to genome positions of Wang et al.... [36]. Table S4. Mean, minimum, maximum and coefficient of variation (CV, in \%) of linkage disequilibrium ( $r 2$ in WM-800, calculated per chromosome, subgenome and across the whole wheat genome. Table S5. Genetic similarity (GS) between founders and WM-800 lines based on 7849 polymorphic SNPs. Table S6. Principle Component Analysis (PCO) based on genetic similarities (GS) between founders and WM-800 lines. Table S7. Distribution of segregation distortion (SD) SNPS and segregation distortion regions (SDR) across the wheat genome and across allele frequency groups. Table S8. Selection of unique SNPs from AFG 1 and AFG 7 in WM-800. Major selection events, represented by $>10$ SNPs, are indicated in bold. (ZIP $2660 \mathrm{~kb}$ )

Additional file 2: Figure S1. Linkage disequilibrium $\left(\mathrm{r}^{2}\right)$ as a function of genetic distance (mean of whole genome) within WM-800. The horizontal line (0.02) indicates the 95 th percentile of the LD distribution of unlinked pairs of loci, representing the population-specific critical $r^{2}$ value. The curve (red line) was fitted with second-degree LOESS. (PNG 30 kb)

\section{Abbreviations}

AFG: Allele frequency group; cM: Centimorgan; $F_{1}$ : First generation after initial cross; $F_{2}$ : Second generation after initial cross; $F_{4}$ : Fourth generation after initial cross; $F_{4: 5}$ : Fifth generation derived from fourth generation; $F_{46:}$ : Sixth generation derived from fourth generation; GA: Gibberellic acid; GB: Giga base; GS: Genetic similarity; GWAS: Genome wide association study; KASP: Kompetitive allele specific PCR; LD: Linkage disequilibrium;

MAGIC: Multi-parent advanced generation intercross; MNI: Mean imputation; NAM: Nested association mapping; PC: Principal component; PCA: Principal component analysis; QTL: Quantitative trait locus/loci; Rht: reduced height; RIL: Recombinant inbred line; SNP: Single nucleotide polymorphism; SSD: Single seed descent

\section{Acknowledgments}

We are grateful to Roswitha Ende, Jana Müglitz, Markus Hinz, Martina Fuhrmann and staff members of RAGT 2n, Silstedt, and Syngenta, Hadmersleben, for excellent technical assistance and to TraitGenetics GmbH, Gatersleben, for genotyping WM-800 with the Infinium iSelect 15 k SNP array.

\section{Authors'contribution}

WS conducted the trait collection in 2015 and 2016, analysed the genotype and phenotype data, carried out the GWAS, created the figures, and drafted the manuscript. AL was involved in data collection in 2016. AM established the GWAS model. JL established the epistatic model. EK and HC developed the MAGIC population. EK planned field trials in 2015 and 2016. JH, HK EE were involved within the development of the population. VK performed the KASP marker analysis. KP acquired the funding, supervised the development of the MAGIC-WHEAT population WM-800 and all analysis. All authors read and approved the final manuscript.

\section{Funding}

This work was supported by the Federal Ministry of Food and Agriculture (project 2814601013).

\section{Availability of data and materials}

Raw data, including data on SNPs and segregation distortion and GWAS, and all other supporting data are provided as additional files. 


\section{Ethics approval and consent to participate}

No human or animal material was used.

Plant material was provided by RAGT $2 n$ and Syngenta Seeds $\mathrm{GmbH}$. The research conducted complied with all institutional and national guidelines.

\section{Consent for publication}

Not applicable.

\section{Competing interests}

The authors declare that they have no competing interests.

\section{Publisher's Note}

Springer Nature remains neutral with regard to jurisdictional claims in published maps and institutional affiliations.

\section{Author details}

'Chair of Plant Breeding, Martin Luther University Halle-Wittenberg, Betty-Heimann Straße 3, 06120 Halle, Germany. ${ }^{2}$ Institute of Crop Science and Resource Conservation, Crop Genetics and Biotechnology Unit, University of Bonn, Katzenburgweg 5, Bonn, Germany. ${ }^{3}$ Syngenta Seeds $\mathrm{GmbH}$, Kroppenstedter Straße 4, 39387 Oschersleben (Bode), Hadmersleben, Germany. ${ }^{4}$ RAGT 2n, Steinesche 5A, 38855 - Silstedt, Wernigerode, Germany. ${ }^{5}$ Secobra Saatzucht GmbH, Feldkirchen 3, 85368 Moosburg an der Isar, Germany. ${ }^{6}$ KWS SAAT SE, Grimsehlstraße 31, 37555 Einbeck, Germany. ${ }^{7}$ KWS LOCHOW GMBH, Ferdinand-Lochow-Straße 5, 29303 Bergen/Wohlde, Germany.

\section{Received: 18 April 2018 Accepted: 2 July 2018}

Published online: 31 July 2018

\section{References}

1. Huang BE, Verbyla KL, Verbyla AP, Raghavan C, Singh VK, Gaur P, Leung H, Varshney RK, Cavanagh CR. MAGIC populations in crops: current status and future prospects. Theor Appl Genet. 2015;128(6):999-1017.

2. Mackay IJ, Bansept-Basler P, Barber T, Bentley AR, Cockram J, Gosman N, Greenland AJ, Horsnell R, Howells R, O'Sullivan DM, et al. An eight-parent multiparent advanced generation inter-cross population for winter-sown wheat: creation, properties, and validation. G3-Genes Genom Genet. 2014; 4(9):1603-10.

3. Yu JM, Holland JB, McMullen MD, Buckler ES. Genetic design and statistical power of nested association mapping in maize. Genetics. 2008;178(1):539-51.

4. Maurer A, Draba V, Jiang Y, Schnaithmann F, Sharma R, Schumann E, Kilian $B$, Reif JC, Pillen K. Modelling the genetic architecture of flowering time control in barley through nested association mapping. BMC Genomics. 2015;16:290

5. Cavanagh C, Morell M, Mackay I, Powell W. From mutations to MAGIC: resources for gene discovery, validation and delivery in crop plants. Curr Opin Plant Biol. 2008;11(2):215-21.

6. Kover PX, Valdar W, Trakalo J, Scarcelli N, Ehrenreich IM, Purugganan MD, Durrant C, Mott R. A multiparent advanced generation inter-cross to fine-map quantitative traits in Arabidopsis thaliana. PLoS Genet. 2009;5(7): e1000551.

7. Bandillo N, Raghavan C, Muyco P, Sevilla M, Lobina I, Dilla-Ermita C, Tung C-W, McCouch S, Thomson M, Mauleon R, et al. Multi-parent advanced generation inter-cross (MAGIC) populations in rice: progress and potential for genetics research and breeding. Rice. 2013;6(1):1-15.

8. Sannemann W, Huang BE, Mathew B, Leon J. Multi-parent advanced generation inter-cross in barley: high-resolution quantitative trait locus mapping for flowering time as a proof of concept. Mol Breeding. 2015;35(3)

9. Dell'Acqua M, Gatti DM, Pea G, Cattonaro F, Coppens F, Magris G, Hlaing AL, Aung $\mathrm{HH}$, Nelissen $\mathrm{H}$, Baute J, et al. Genetic properties of the MAGIC maize population: a new platform for high definition QTL mapping in Zea mays. Genome Biol. 2015;16:167.

10. Pascual L, Desplat N, Huang BE, Desgroux A, Bruguier L, Bouchet JP, Le QH, Chauchard B, Verschave P, Causse M. Potential of a tomato MAGIC population to decipher the genetic control of quantitative traits and detect causal variants in the resequencing era. Plant Biotechnol J. 2015;13(4):565-77.

11. Huang BE, George AW, Forrest KL, Kilian A, Hayden MJ, Morell MK, Cavanagh CR. A multiparent advanced generation inter-cross population for genetic analysis in wheat. Plant Biotechnol J. 2012;10(7):826-39.
12. Milner SG, Maccaferri M, Huang BE, Mantovani P, Massi A, Frascaroli E, Tuberosa R, Salvi S. A multiparental cross population for mapping QTL for agronomic traits in durum wheat (Triticum turgidum ssp durum). Plant Biotechnol J. 2016;14(2):735-48.

13. Gardner KA, Wittern LM, Mackay IJ. A highly recombined, high-density, eight-founder wheat MAGIC map reveals extensive segregation distortion and genomic locations of introgression segments. Plant Biotechnol J. 2016;

14. Huang BE, George AW. R/mpMap: a computational platform for the genetic analysis of multiparent recombinant inbred lines. Bioinformatics. 2011;27(5): 727-9.

15. Camargo AV, Mott R, Gardner KA, Mackay IJ, Corke F, Doonan JH, Kim JT, Bentley AR. Determining Phenological patterns associated with the onset of senescence in a wheat MAGIC mapping population. Front Plant Sci. 2016;7

16. Würschum T, Langer SM, Longin CFH. Genetic control of plant height in European winter wheat cultivars. Theor Appl Genet. 2015;128(5):865-74.

17. Buerstmayr M, Lemmens $M$, Steiner B, Buerstmayr $H$. Advanced backcross QTL mapping of resistance to fusarium head blight and plant morphological traits in a Triticum macha $x$ T. Aestivum population. Theor Appl Genet. 2011;123(2):293-306.

18. Hedden P. The genes of the green revolution. Trends Genet. 2003;19(1):5-9.

19. Flintham JE, Borner A, Worland AJ, Gale MD. Optimizing wheat grain yield: effects of Rht (gibberellin-insensitive) dwarfing genes. J Agr Sci. 1997;128:11-25.

20. Worland AJ, Law CN. Genetic-analysis of chromosome $2 d$ of wheat .1. The location of genes affecting height, day-length insensitivity, hybrid dwarfism and yellow-rust resistance. Z Pflanzenzucht. 1986;96(4):331-45.

21. Konzak C: Evaluation and Genet Anal of semi-dwarf mutants of wheat. In.; 1982.

22. Worland AJ, Law CN, Shakoor A. The genetic-analysis of an induced height mutant in wheat. Heredity. 1980;45(Aug):61-71.

23. Worland A, Law C, Petrovic S. Height reducing genes and their importance to Yugoslavian winter wheat varieties. Savremena poljoprivreda. 1990;

24. Konzak C. Rht-genes. Ann Wheat Newsletter. 1987;33:174-5.

25. Sutka J, Kovacs G. Chromosomal location of dwarfing gene Rht12 in wheat. Euphytica. 1987;36(2):521-3.

26. Zanke CD, Ling J, Plieske J, Kollers S, Ebmeyer E, Korzun V, Argillier O, Stiewe $\mathrm{G}$, Hinze M, Neumann $\mathrm{K}$, et al. Whole genome association mapping of plant height in winter wheat (Triticum aestivum L.). PLoS One. 2014;9(11)

27. Griffiths S, Simmonds J, Leverington M, Wang YK, Fish L, Sayers L, Alibert L, Orford S, Wingen L, Snape J. Meta-QTL analysis of the genetic control of crop height in elite European winter wheat germplasm. Mol Breeding. 2012;29(1):159-71.

28. Xing Y, Tan Y, Hua J, Sun X, Xu C, Zhang Q. Characterization of the main effects, epistatic effects and their environmental interactions of QTLs on the genetic basis of yield traits in rice. Theor Appl Genet. 2002;105(2-3):248-57.

29. Durand E, Bouchet S, Bertin P, Ressayre A, Jamin P, Charcosset A, Dillmann C, Tenaillon MI. Flowering time in maize: linkage and epistasis at a major effect locus. Genetics. 2012;190(4):1547.

30. Stich B, Gebhardt C. Detection of epistatic interactions in association mapping populations: an example from tetraploid potato. Heredity (Edinb). 2011;107(6):537-47.

31. von Korff M, Leon J, Pillen K. Detection of epistatic interactions between exotic alleles introgressed from wild barley (H. Vulgare ssp. spontaneum). Theor Appl Genet. 2010;121(8):1455-64.

32. Reif JC, Maurer HP, Korzun V, Ebmeyer E, Miedaner T, Wurschum T. Mapping QTLs with main and epistatic effects underlying grain yield and heading time in soft winter wheat. Theor Appl Genet. 2011:123(2):283-92.

33. Maccaferri M, Sanguineti MC, Corneti S, Ortega JLA, Ben Salem M, Bort J, DeAmbrogio E, del Moral LFG, Demontis A, El-Ahmed A, et al. Quantitative trait loci for grain yield and adaptation of durum wheat (Triticum durum Desf.) across a wide range of water availability. Genetics. 2008;178(1):489-511.

34. He S, Schulthess AW, Mirdita V, Zhao Y, Korzun V, Bothe R, Ebmeyer E, Reif $J C$, Jiang Y. Genomic selection in a commercial winter wheat population. Theor Appl Genet. 2016;129(3):641-51.

35. Jiang Y, Reif JC. Modeling epistasis in genomic selection. Genetics. 2015; 201(2):759-68

36. Wang S, Wong D, Forrest K, Allen A, Chao S, Huang BE, Maccaferri M, Salvi S, Milner SG, Cattivelli $L$, et al. Characterization of polyploid wheat genomic diversity using a high-density 90000 single nucleotide polymorphism array. Plant Biotechnol J. 2014;12(6):787-96.

37. Miyagawa T, Nishida N, Ohashi J, Kimura R, Fujimoto A, Kawashima M, Koike A, Sasaki T, Tanii H, Otowa T, et al. Appropriate data cleaning methods for genome-wide association study. J of hum genet. 2008;53(10):886-93. 
38. Rutkoski JE, Poland J, Jannink JL, Sorrells ME. Imputation of unordered markers and the impact on genomic selection accuracy. G3-Genes Genom Genet. 2013;3(3):427-39.

39. Holm S, Simple Sequentially A. Rejective multiple test procedure. Scand J Stat. 1979;6(2):65-70.

40. Paillard S, Schnurbusch T, Winzeler M, Messmer M, Sourdille P, Abderhalden $\mathrm{O}$, Keller B, Schachermayr G. An integrative genetic linkage map of winter wheat (Triticum aestivum L.). Theor Appl Genet. 2003;107(7):1235-42.

41. Pritchard JK, Przeworski M. Linkage disequilibrium in humans: Models and data. Am J Hum Genet. 2001;69(1):1-14.

42. Breseghello F, Sorrells ME. Association mapping of kernel size and milling quality in wheat (Triticum aestivum L.) cultivars. Genetics. 2006;172(2):1165-77.

43. Liu WX, Gowda M, Steinhoff J, Maurer HP, Wurschum T, Longin CFH, Cossic F, Reif JC. Association mapping in an elite maize breeding population. Theor Appl Genet. 2011;123(5):847-58

44. Maurer A, Sannemann W, Leon J, Pillen K. Estimating parent-specific QTL effects through cumulating linked identity-by-state SNP effects in multiparental populations. Heredity. 2016

45. Kearsey MPH. Genetical analysis of quantitative traits. Garland Science. 1996;

46. lehisa JCM, Shimizu A, Sato K, Nishijima R, Sakaguchi K, Matsuda R, Nasuda S, Takumi S. Genome-wide marker development for the wheat D genome based on single nucleotide polymorphisms identified from transcripts in the wild wheat progenitor Aegilops tauschii. Theor Appl Genet. 2014;127(2):261-71.

47. Neumann K, Kobiljski B, Dencic S, Varshney RK, Borner A. Genome-wide association mapping: a case study in bread wheat (Triticum aestivum L.). Mol Breeding. 2011;27(1):37-58.

48. Würschum T, Langer SM, Longin CF, Korzun V, Akhunov E, Ebmeyer E, Schachschneider R, Schacht J, Kazman E, Reif JC. Population structure, genetic diversity and linkage disequilibrium in elite winter wheat assessed with SNP and SSR markers. Theor Appl Genet. 2013;126(6):1477-86.

49. Pariyar SR, Dababat AA, Sannemann W, Erginbas-Orakci G, Elashry A, Siddique S, Morgounov A, Leon J, Grundler FM: Genome-wide association study in wheat identifies resistance to the cereal cyst nematode Heterodera filipjevi. Phytopathology 2016:PHYTO02160054FI.

50. Chao SM, Dubcovsky J, Dvorak J, Luo MC, Baenziger SP, Matnyazov R, Clark DR, Talbert LE, Anderson JA, Dreisigacker S, et al. Population- and genomespecific patterns of linkage disequilibrium and SNP variation in spring and winter wheat (Triticum aestivum L.). BMC Genomics. 2010;11

51. Li HB, Kilian A, Zhou MX, Wenzl P, Huttner E, Mendham N, McIntyre L, Vaillancourt RE. Construction of a high-density composite map and comparative mapping of segregation distortion regions in barley. Mol Gen Genomics. 2010;284(5):319-31.

52. Dreissig S, Fuchs J, Himmelbach A, Mascher M, Houben A. Sequencing of single pollen nuclei reveals meiotic recombination events at Megabase resolution and circumvents segregation distortion caused by Postmeiotic processes. Front Plant Sci. 2017:8:1620

53. Alheit KV, Reif JC, Maurer HP, Hahn V, Weissmann EA, Miedaner T, Wurschum T. Detection of segregation distortion loci in triticale ( $\mathrm{x}$ Triticosecale Wittmack) based on a high-density DArT marker consensus genetic linkage map. BMC Genomics. 2011;12

54. Li HH, Vikram P, Singh RP, Kilian A, Carling J, Song J, Burgueno-Ferreira JA, Bhavani S, Huerta-Espino J, Payne T, et al. A high density GBS map of bread wheat and its application for dissecting complex disease resistance traits. BMC Genomics. 2015;16

55. Xu SZ. Quantitative trait locus mapping can benefit from segregation distortion. Genetics. 2008;180(4):2201-8.

56. Belanger S, Esteves P, Clermont I, Jean M, Belzile F. Genotyping-bysequencing on pooled samples and its use in measuring segregation Bias during the course of Androgenesis in barley. Plant Genome. 2016;9(1)

57. Bomblies K, Weigel D. Hybrid necrosis: autoimmunity as a potential geneflow barrier in plant species. Nat Rev Genet. 2007:8(5):382-93.

58. Chae E, Tran DTN, Weigel D. Cooperation and conflict in the plant immune system. PLoS Pathog. 2016;12(3)

59. Swiadek M, Proost S, Sieh D, Yu J, Todesco M, Jorzig C, Cubillos AER, Plotner B, Nikoloski Z, Chae E, et al. Novel allelic variants in ACD6 cause hybrid necrosis in local collection of Arabidopsis thaliana. New Phytol. 2017;213(2):900-15.

60. Cadalen T, Boeuf C, Bernard S, Bernard M. An intervarietal molecular marker map in Triticum aestivum L. Em. Thell. And comparison with a map from a wide cross. Theor Appl Genet. 1997;94(3-4):367-77.

61. Campbell KG, Bergman CJ, Gualberto DG, Anderson JA, Giroux MJ, Hareland G, Fulcher RG, Sorrells ME, Finney PL. Quantitative trait loci associated with kernel traits in a softx hard wheat cross. Crop Sci. 1999;39(4):1184-95.
62. Kammholz SJ, Campbell A, Sutherland M, Hollamby G, Martin P, Eastwood R, Barclay I, Wilson R, Brennan P, Sheppard J. Establishment and characterisation of wheat genetic mapping populations. Crop and Pasture Science. 2001;52(12):1079-88.

63. Groos C, Gay G, Perretant M-R, Gervais L, Bernard M, Dedryver F, Charmet G. Study of the relationship between pre-harvest sprouting and grain color by quantitative trait loci analysis in a whitex red grain bread-wheat cross. Theor Appl Genet. 2002;104(1):39-47.

64. Cavanagh CR, Chao S, Wang S, Huang BE, Stephen S, Kiani S, Forrest K, Saintenac C, Brown-Guedira GL, Akhunova A, et al. Genome-wide comparative diversity uncovers multiple targets of selection for improvement in hexaploid wheat landraces and cultivars. P Natl Acad Sci USA. 2013;110(20):8057-62.

65. Uauy C. Wheat genomics comes of age. Curr Opin Plant Biol. 2017;36:142-8.

66. Krasileva KV, Vasquez-Gross HA, Howell T, Bailey P, Paraiso F, Clissold L, Simmonds J, Ramirez-Gonzalez RH, Wang XD, Borrill P, et al. Uncovering hidden variation in polyploid wheat. P Natl Acad Sci USA. 2017;114(6):E913-21.

67. BenAmer IM, Korzun V, Worland AJ, Borner A. Genetic mapping of QTL controlling tissue-culture response on chromosome $2 \mathrm{~B}$ of wheat (Triticum aestivum L.) in relation to major genes and RFLP markers. Theor Appl Genet. 1997;94(8):1047-52.

68. Xu Y, Zhu L, Xiao J, Huang N, McCouch S. Chromosomal regions associated with segregation distortion of molecular markers in F2, backcross, doubled haploid, and recombinant inbred populations in rice (Oryza sativa L.). Mol Gen Genet. 1997:253(5):535-45.

69. Lu H, Romero-Severson J, Bernardo R: Chromosomal regions associated with segregation distortion in maize. Theor App/ Genet;105(4):622-628.

70. Luo L, Xu S. Mapping viability loci using molecular markers. Heredity. 2003; 90(6):459-67.

71. Zhu CS, Wang CM, Zhang YM. Modeling segregation distortion for viability selection I. Reconstruction of linkage maps with distorted markers. Theor Appl Genet. 2007;114(2):295-305.

72. Xue SL, Zhang ZZ, Lin F, Kong ZX, Cao Y, Li CJ, Yi HY, Mei MF, Zhu HL, Wu $J$, et al. A high-density intervarietal map of the wheat genome enriched with markers derived from expressed sequence tags. Theor Appl Genet. 2008:117(2):181-9.

73. Li CL, Bai GH, Chao SM, Wang ZH. A high-density SNP and SSR consensus map reveals segregation distortion regions in wheat. Biomed Res Int. 2015;

74. Ellis MH, Spielmeyer W, Gale KR, Rebetzke GJ, Richards RA. "perfect" markers for the Rht-B1b and Rht-D1b dwarfing genes in wheat. Theor Appl Genet. 2002;105(6-7):1038-42.

75. Worland AJ, Korzun V, Roder MS, Ganal MW, Law CN. Genetic analysis of the dwarfing gene Rht8 in wheat. Part II. The distribution and adaptive significance of allelic variants at the Rht8 locus of wheat as revealed by microsatellite screening. Theor Appl Genet. 1998;96(8):1110-20.

76. Würschum T, Langer SM, Longin CFH, Tucker MR, Leiser WL. A modern green revolution gene for reduced height in wheat. Plant J. 2017;

77. Herter CP, Ebmeyer E, Kollers S, Korzun V, Leiser WL, Wurschum T, Miedaner T. Rht24 reduces height in the winter wheat population 'Solitar $x$ Bussard' without adverse effects on fusarium head blight infection. Theor Appl Genet. 2018:131(6):1263-72.

78. Wilhelm EP, Boulton MI, Al-Kaff N, Balfourier F, Bordes J, Greenland AJ, Powell W, Mackay IJ. Rht-1 and Ppd-D1 associations with height, GA sensitivity, and days to heading in a worldwide bread wheat collection. Theor Appl Genet. 2013;126(9):2233-43.

79. Maurer A, Draba V, Pillen K. Genomic dissection of plant development and its impact on thousand grain weight in barley through nested association mapping. J Exp Bot. 2016;67(8):2507-18.

80. Tuinstra MR, Ejeta G, Goldsbrough PB. Heterogeneous inbred family (HIF) analysis: a method for developing near-isogenic lines that differ at quantitative trait loci. Theor Appl Genet. 1997;95(5-6):1005-11.

81. Liu NN, Liu JX, Li WQ, Pan QC, Liu J, Yang XH, Yan JB, Xiao YJ. Intraspecific variation of residual heterozygosity and its utility for quantitative genetic studies in maize. BMC Plant Biol. 2018;18

82. Carlborg O, Haley CS. Epistasis: too often neglected in complex trait studies? Nat Rev Genet. 2004;5(8):618-U614

83. Buckler ES, Holland JB, Bradbury PJ, Acharya CB, Brown PJ, Browne C, Ersoz E, Flint-Garcia S, Garcia A, Glaubitz JC, et al. The genetic architecture of maize flowering time. Science. 2009;325(5941):714-8.

84. Baenziger PS, McMaster GS, Wilhelm WW, Weiss A, Hays CJ. Putting genes into genetic coefficients. Field Crop Res. 2004;90(1):133-43. 
85. Wu XS, Wang ZH, Chang XP, Jing RL. Genetic dissection of the developmental behaviours of plant height in wheat under diverse water regimes. J Exp Bot. 2010;61(11):2923-37.

86. Zhang K, Tian J, Zhao L, Wang S. Mapping QTLs with epistatic effects and QTL x environment interactions for plant height using a doubled haploid population in cultivated wheat. J genet genomics. 2008;35(2):119-27.

87. Sherman JD, Martin JM, Blake NK, Lanning SP, Talbert LE. Genetic basis of agronomic differences between a modern and a historical spring wheat cultivar. Crop Sci. 2014;54(1):1-13.

88. Ma XQ, Tang JH, Teng WT, Yan JB, Meng YJ, Li JS. Epistatic interaction is an important genetic basis of grain yield and its components in maize. Mol Breeding. 2007;20(1):41-51.

89. Beales J, Turner A, GriYths S, Snape JW, Laurie DA. A pseudo-response regulator is misexpressed in the photoperiod insensitive Ppd-D1a mutant of wheat (Triticum aestivum L.). Theor Appl Genet. 2007;115(5):721-33.

Ready to submit your research? Choose BMC and benefit from:

- fast, convenient online submission

- thorough peer review by experienced researchers in your field

- rapid publication on acceptance

- support for research data, including large and complex data types

- gold Open Access which fosters wider collaboration and increased citations

- maximum visibility for your research: over $100 \mathrm{M}$ website views per year

At BMC, research is always in progress.

Learn more biomedcentral.com/submissions 